\title{
O programa de unidade de polícia pacificadora como instrumento do projeto de cidade competitiva
}

The program of peacemaker police unit as an instrument of a competitive city project

Referência: Almeida, Adilson (2018). O programa de unidade de polícia pacificadora como instrumento do projeto de cidade competitiva. Revista de Geografia e Ordenamento do Território (GOT), n. ${ }^{\circ} 15$ (dezembro). Centro de Estudos de Geografia e Ordenamento do Território, p. 5-29, dx.doi.org/10.17127/got/2018.15.001

\section{RESUMO}

O presente artigo tem como objetivo trazer a lume evidências da hipótese de que 0 programa de Unidade de Polícia Pacificadora possui como um de seus fins o de ser instrumento para a consolidação de programa de planejamento estratégico adotado na cidade do Rio de Janeiro, que tem como um de seus pressupostos difundir a imagem de cidade segura, com condições para receber grandes eventos e, principalmente, ser atrativa ao mercado e aos grandes investimentos. Para tanto, a análise da inviabilidade econômica do programa revelará que não poderia ser implantado e mantido em todos os territórios com critérios idênticos, o que inevitavelmente determinou a seletividade. Por fim, como ratificação desta seletividade, demonstrar-se-á em quais áreas da cidade as unidades foram implantadas e as motivações.

Palavras-chave: Rio de Janeiro; políticas públicas; segurança pública; Unidades de Polícia Pacificadora; neoliberalismo; cidades competitivas.

\section{ABSTRACT}

The purpose of this article is to discuss the targets of the Peacekeeping Police Unit Program as a consolidation instrument of the strategic planning schedule adopted in Rio de Janeiro, which aims to deliver a image of a safe city, with conditions to host large-scale events and, first and foremost, to be attractive to the market and to large investors. For this, we develop the thesis, based on the analysis of its economic viability, that the Peacekeeping Police Unit Program could not be uniformly implemented and maintained in all urban areas, claiming the use of selective criteria. In conclusion, it will be presented the specific urban areas where the mentioned program was installed, and the motivation beneath the elections of these areas.

Keywords: Rio de Janeiro; public policies; public security; Peacekeeping Police Units; neoliberalism; competitive cities. 


\section{A evolução do cenário econômico-político internacional, o atual protagonismo das cidades e o contexto carioca}

Desde a década de 70 o cenário financeiro-econômico mundial tem passado por profundas transformações que ocorrem de forma concomitante a forte processo de globalização. Em período imediatamente anterior, que se iniciou com o fim da II Guerra Mundial, a Europa adotou modelo que viria a se denominar welfare state (estado de bem-estar social), que teve como principal expoente John Maynard Keynes.

O modelo nominado de keynesiano, apesar de proporcionar diversos ganhos no campo social, tinha como principal motivador a manutenção do sistema capitalista sem que houvesse grandes crises, como a ocorrida no ano de 1929. Dessa forma, a existência de um Estado que garantisse o bem-estar das pessoas e que fosse o grande propulsor do desenvolvimento econômico eram condições imprescindíveis para evitar ciclos de crises.

No entanto, em que pese os esforços empreendidos, na década de 70 uma forte crise abalou as economias dos Estados Nacionais, cenário perfeito para que os liberais propusessem um novo modelo econômico. Margaret Thatcher (Reino Unido) e Ronald Reagen (EUA), durante a década de 80, iniciaram profundas reformas com vistas a liberalizar os mercados e pregar a austeridade fiscal (Estado mínimo), o que ocasionou a interrupção de diversas políticas públicas promovidas pelos respectivos Estados, cujos setores passaram a ser regidos pelas regras do livre mercado.

Ao mesmo tempo em que a figura do Estado desenvolvimentista perdia força, surge o Consenso de Washington (recomendação internacional elaborada em 1989, que visava a propalar a conduta econômica neoliberal com a intenção de combater as crises e misérias dos países subdesenvolvidos, sobretudo os da América Latina), o qual exigia ajustes estruturais que determinaram o corte de orçamentos para áreas de assistência e de desenvolvimento social e que, por consequência, acabaram por enfraquecer os programas de Estado nesse setor. De outro modo, em favor da lógica de mercado, caracterizada essencialmente pela concessão de empréstimos, o Estado procura eximir-se de intervir em diversas questões, como a privatização de empresas públicas que atuam em setores 
estratégicos da economia. Na sequência, outras posturas são exigidas dos Estados, como a flexibilização das relações de trabalho, pautada na figura da relação empresa x empregado.

No mesmo período, percebeu-se o movimento de financeirização que acompanhou o novo modelo neoliberal que se iniciou na década de 70 e que se caracteriza num aumento exponencial das transações financeiras, liberalização e desregulamentação de mercados e das atividades financeiras, com o concomitante aumento da importância ao capital financeiro.

Como se pôde depreender, os Estados Nacionais perdem força como centro de poder, passando da figura de regulador para a de facilitador do mercado e dependente deste. Por outro viés, as cidades começam a ganhar importância, não como figura que possa se contrapor ao mercado, mas como terreno fértil para o desenvolvimento das práticas neoliberais. As cidades começaram a ganhar destaque no cenário internacional, possuindo grande autonomia frente aos Estados-nações aos quais estão vinculadas e não é por acaso que o planejamento estratégico na Administração Pública ganhou força e começou a ser adotado como modelo de gestão, pois tem como um dos pilares fomentar a mercantilização e a financeirização do mercado da cidade.

Nesse contexto em que a cidade passa a ser produzida a partir do paradigma neoliberal de cidade-empresa, o planejamento como política pública de Estado dá lugar ao empreendedorismo como pensamento dominante na produção da cidade (HARVEY, 2006) e a escala urbana passa a exercer cada vez mais centralidade nas economias nacionais. Para Harvey, como consequência da redução das barreiras espaciais à circulação de bens, pessoas, dinheiro e informação no último terço do século $X X$, a qualidade do espaço ganha importância para a inserção das cidades nos espaços econômicos globais. Em um cenário de competição interurbana, essa qualidade passa a ser decisiva na atração do capital com vistas ao desenvolvimento capitalista (HARVEY, 1996, p. 48-64). Em busca de investimentos, as cidades que adotam o modelo inserem-se num ambiente competitivo internacional o que requer a divulgação de uma boa imagem.

Inspirada nos princípios de gestão empresarial da Harvard Business School, emerge a figura do planejamento estratégico de cidade - de acordo com a caracterização feita por autores como Vainer (2000) e Harvey (2006). Neste processo, em que "cidades [são] submetidas às 
mesmas condições e desafios que as empresas" (VAINER, 2000, p. 76), exige-se que os governos locais sejam flexíveis, facilmente adaptáveis à dinâmica da globalização.

Nesse novo modo de planejar, Vainer (2000) afirma que a cidade se caracteriza como uma mercadoria, com a venda de seus atributos e o marketing como promovedor de sua atratividade, funcionamento que se assemelha ao de uma empresa. Outra característica marcante é o estreitamento das parcerias público-privada.

Acerca das parcerias público-privada, hodiernamente discute-se se este mecanismo teria aprofundado o desvirtuamento do interesse público. Acerca do tema, Fernandes e Chamusca (2014) afirmam que na última década aumenta-se a dependência em relação ao capital privado e nota-se uma transformação - das parcerias público-privada designadamente - que responde em larga medida à vontade do investidor, num processo de "privatização da cidade" (apud Chamusca, 2012) que ocorre no quadro de uma política de regeneração onde se verifica o "triunfo da arquitetura sobre a geografia económica e social" (apud Fernandes, 2006).

Realizado esse pequeno esboço introdutório que revela o cenário econômico internacional e o modo como as cidades se inserem neste cenário competitivo, passa-se a análise específica do contexto carioca.

\section{1. $O$ contexto carioca}

No caso da cidade do Rio de Janeiro, as ações públicas que desejam tornar a cidade atrativa aos investimentos passam necessariamente pela questão da segurança pública e da capacidade de sediar grandes eventos (Pan-americanos, Jogos Olímpicos, jogos da Copa do Mundo de Futebol, exposições e desfiles internacionais), bem como pela revitalização de espaços públicos, como o caso do Porto Maravilha, e a criação do que se qualifica como espaços de ócio. As duas administrações públicas, municipal e estadual, ambas comandadas pelo Partido do Movimento Democrático Brasileiro (PMDB), atual MDB (Movimento Democrático Brasileiro), estavam alinhadas com programa que veiculasse a imagem do Estado e, principalmente, da cidade do Rio de Janeiro no cenário internacional como apta a atrair empresas e investimentos. 
Desse modo, o primeiro passo foi concorrer e ser eleita para sediar grandes eventos, tendo a cidade do Rio de Janeiro sido escolhida para sediar alguns jogos e a grande final da Copa do Mundo de Futebol FIFA que se realizou no ano de 2014. Como se não bastasse, a cidade do Rio de Janeiro concorreu e venceu pleito em 2009 para sediar os Jogos Olímpicos de 2016. A justificativa das autoridades (Presidente da República, Governador e Prefeito) é que esta seria uma grande oportunidade para atrair investimentos e colocar em evidência, principalmente, o nome da cidade do Rio de Janeiro no mundo, além do tão famoso "legado olímpico", que seria fruto de intervenções urbanísticas.

No entanto, clima de extrema insegurança está vinculado à imagem da cidade e tanto o Estado como a Cidade do Rio de Janeiro vinham ano após ano com cenário de redução de investimentos privados e de perda de empresas.

O quadro atual da segurança na cidade do Rio de Janeiro é fruto de mais de um século em que a urbanização da cidade do Rio de Janeiro é marcada pela exclusão social, como se pode depreender do período higienista do início do século XX e da elitização pelo qual passou o centro da cidade, ocasião em que a população mais vulnerável foi "empurrada" para a periferia e morros cariocas. No entanto, as especificidades do atual cenário têm sua origem na década de 80 , quando os assentamentos precários, denominados popularmente como "favelas", começam a ser ocupados por facções criminosas ligadas ao tráfico de drogas, que encontram nestes ambientes, ante a ausência de Estado, campo propício ao desenvolvimento de suas práticas.

A disputa por pontos de vendas de drogas, conhecidas por "bocas de fumo", entre as facções criminosas, e as políticas de segurança pública pautadas no enfrentamento, acrescentaram mais um elemento relevante para a sensação de profunda insegurança na cidade, que é o comércio ilegal de armas. A necessidade de defesa e tomada destes pontos de venda e o enfrentamento da Polícia requerem o uso da força, que se dá por meio de armas de fogo. Assim, conflitos armados e a elevada taxa de homicídios, com destaque para a morte de jovens, negros e pobres, frutos da exclusão, passam a ser um retrato da cidade.

Carvalho nos traz valiosa contribuição para o debate, ao afirmar que (MACHADO DA SILVA e LEITE, 2008, apud CARVALHO, 2013, p. 288): 
extremamente violenta devido a uma série de acontecimentos que envolviam principalmente o conflito de drogas do varejo e a polícia, além de assaltos, sequestros, homicídios, dentre outras modalidades de crime que eram constantemente veiculados em diversos meios de comunicação.

Ainda sobre o tema, Carvalho (2013, p. 288) destaca a obra do jornalista Zuenir Ventura, na qual a imagem de cidade maravilhosa foi gradualmente sendo substituída pela de cidade partida. A razão seria a divisão socioeconômica da cidade entre área nobre (ricos e classe média), tidas como vítimas da violência, e os morros e favelas onde viveriam as camadas sociais mais pobres, identificados como os territórios promovedores da violência, com o consequente reforço do equivocado vínculo simbólico entre pobreza e marginalidade.

As promessas de campanha feitas no ano de 2006 pelo então candidato do PMDB, eleito naquele ano ao cargo de Governador ${ }^{1}$, refletem bem referidas preocupações, pois têm como principais focos a segurança pública e a reversão do quadro de êxodo de empresas do Estado, por meio da atração de investimentos. Na esfera municipal, no mesmo ano em que foi escolhida para sediar dos Jogos Olímpicos de 2016, a Administração Municipal lançou o Plano Estratégico da Prefeitura do Rio de Janeiro (2009-2012) com o slogan "O Rio mais integrado e competitivo" ${ }^{2}$. Tais informações, quando conjugadas no tempo e espaço (concomitância do período das administrações e o território para o qual as políticas são direcionadas), revelam a afinidade entre as administrações para propagar a imagem da cidade segura e atrativa aos investimentos. O próprio documento de apresentação do referido plano estratégico menciona na parte do diagnóstico de emprego e renda que há um grave desequilíbrio no nível e no dinamismo econômico entre as diversas regiões da cidade e aponta com uma das causas os índices de criminalidade ${ }^{3}$.

Assim, como muito bem idealizado por Vainer (2000), havia a solidificação da ideia de crise (caos na segurança pública) para, então, os governos gozarem de legitimidade para desenvolver programas que resultem na percepção de ausência de conflitos e de coesão entre os cidadãos da cidade, como estratégia de markenting urbano dominante para a promoção da cidade atrativa e segura, inserindo-a no contexto de mercadoria. Como

\footnotetext{
1 Jornal O Globo. Infoglobo Comunicação e Participações S/A (1996-2018). Disponível em: https://oglobo.globo.com/brasil/eleicoes-2006/confira-as-propostas-de-sergio-cabral-para-governo-5004575

${ }^{2}$ Rio Como Vamos. Disponível em http://www.riocomovamos.org.br/arq/planejamento estrategico.pdf

${ }^{3}$ Rio Como Vamos. Disponível em http://www.riocomovamos.org.br/arq/planejamento_estrategico.pdf, p. 70.
} 
exposto alhures, o cenário carioca oferecia condições propícias a legitimar programas na área de segurança voltados à lógica do mercado mesmo que repentinamente elaborados.

O Rio estava diante de um grande desafio, que era o de promover dois grandes eventos (Copa do Mundo de Futebol e Olimpíadas), além de outros de menor proporção que surgiriam ao longo do período de preparação da cidade para os referidos megaeventos, no que se costuma denominar de laboratórios ou eventos testes. Para tanto, além de intervenções urbanísticas necessárias, a cidade teria a grande possibilidade de veicular sua imagem ao mundo e, na lógica das administrações públicas, o desejo era o de um local atrativo aos grandes investimentos. Essa imagem, ante o histórico de violência da cidade e de acordo com a lógica do mercado, passa necessariamente pela imagem de cidade segura e com coesão social e é exatamente neste contexto que surge o Programa de Unidades de Polícia Pacificadora, conhecida pela sigla UPP.

O Programa de Unidades de Polícia Pacificadora foi criado no ano de 2008, após a escolha da cidade para sediar alguns jogos e a grande final da Copa do Mundo de Futebol Fifa, a ser realizada no ano de 2014, e oficialmente qualifica-se como programa que visa a retomada permanente de comunidades dominadas pelo tráfico de drogas e a proximidade do Estado com estas populações, que se daria por meio do conceito de polícia de proximidade, que vai além do de polícia comunitária e tem sua estratégia fundamentada na parceria entre a população e instituições de segurança pública.

Carvalho (2013, p. 287-288) salienta que “o investimento na área de segurança pública está relacionado à tentativa de mudar a imagem da cidade e assegurar aos comitês organizadores da Copa do Mundo e dos Jogos Olímpicos que o Rio de Janeiro está seguro no que diz respeito à violência urbana". Denota-se que a segurança pública no Rio de Janeiro é tida como área estratégica no câmbio da imagem da cidade para refleti-la como segura para realizar grandes eventos e aos investimentos. Para tanto, CARVALHO enfatiza que não foi à toa o fato de a Capitã da UPP Santa Marta, primeira unidade do programa instalada em dezembro de 2008 no bairro de Botafogo, zona sul do município do Rio de Janeiro, integrar o Comitê Olímpico Brasileiro (COB) na sessão de escolha da cidade do Rio de Janeiro para sediar os jogos olímpicos. 
Pelo exposto, para a execução dos objetivos é evidente e necessária a parceria entre Governo de Estado e a Prefeitura da Cidade do Rio de Janeiro que, como citado alhures, eram administrados pelo mesmo partido político. Perceber referida parceria é importante para compreender como o Programa de Unidade de Polícia Pacificadora tinha como principal objetivo garantir os megaeventos na cidade e proporcionar a imagem de cidade segura e apta a receber investimentos, pois a atribuição para a execução de programas de segurança pública extrapola o âmbito de competências do governo municipal.

Nesse âmbito, em que pese a Administração Municipal possuir o corpo de Guarda Municipal, cujo foco é a proteção do patrimônio público e o auxílio na prevenção de pequenos delitos, é de responsabilidade dos Estados gerir a questão da segurança pública em seus territórios, conforme preconiza o artigo 144 da Constituição Federal de $1988^{4}$. Este quadro, somado ao fato de que a cidade do Rio de Janeiro necessitava transmitir a imagem de segurança, revela que a parceria entre as duas administrações era imprescindível para a consecução do projeto de cidade segura.

O urbanismo empresarial visa possibilitar a adoção de modelo em que os mercados direcionem as políticas públicas, passando o foco das referidas políticas na ideia da obtenção de lucro. Desse modo, formular programa de segurança pública com aptidão para gerar a imagem de cidade segura, somado a outras medidas de incentivo ao investimento privado, como as desonerações fiscais a específicos setores do mercado, que foram largamente utilizadas nas gestões do Governo do Estado (2007-2010 e 2011-2014) , eram fundamentais como sinalização para o mercado e para a realização dos grandes eventos, sendo este último importantíssima "vitrine" do mercado da cidade num contexto competitivo entre cidades.

\footnotetext{
4 Presidência da República. Disponível em: http://www.planalto.gov.br/ccivil_03/constituicao/ constituicaocompilado.htm?TSPD_101_R0=34ee2ce0d27831a798ae04e6735c2191d8300000000000000003ec 5d2b3ffff0000000 $0000000000000000000005 a a f 39 e 60062880 a 77$

5 Portal G1. Globo Comunicação e Participações S/A (2000-2018). Disponível em: http://g1.globo.com /rio-dejaneiro/noticia/2016/03/rj-deixou-de-arrecadar-r-138-bi-em-icms-entre-2008-e-2013-diz-tce.html
} 


\section{Formas de controle dos desviantes e a manutenção da ordem econômica imposta}

De acordo com Max Weber, o Estado é o detentor do monopólio da violência dentro de um território, fruto do poder soberano. Assim, numa compreensão clássica, a instituição policial seria um aparato estatal que detém o monopólio da coação física legítima, colocando, portanto, no centro da ideia de polícia a possibilidade de uso da violência (VALENTE, 2016, p.82).

Michel Foucault vai além, ao afirmar que a instituição policial não deve ser vista tão somente sob o aspecto do uso da força, mas sob o ponto de vista das relações de governo (SOZZO, 2012, p.513, apud VALENTE, 2016, p. 82). Referidas relações de governo anunciam o conceito de "governamentalidade" introduzido por Foucault, que seriam mecanismos de poder que têm por alvo a população, por forma de saber a economia política e por instrumentos os dispositivos de segurança (VALENTE, 2016, p. 82).

Foucault aduziu que:

Por esta palavra, "governamentalidade", entendo o conjunto constituído pelas instituições, os procedimentos, análises e reflexões, os cálculos e as táticas que permitem exercer essa forma bem específica, embora muito complexa, de poder que tem por alvo principal a população, por principal forma de saber a economia política e por instrumento técnico essencial os dispositivos de segurança. Em segundo lugar, por "governamentalidade" entendo a tendência, a linha de força que, em todo o ocidente, não parou de conduzir, e desde há muito, para a preeminência desse tipo de poder que chamar de "governo" sobre todos os outros - soberania, disciplina - e que trouxe, por um lado, o desenvolvimento de toda uma série de aparelhos específicos de governo de, por outro lado, o desenvolvimento de toda uma série de saberes. Enfim, por "governamentalidade" creio que se deveria entender o processo, ou antes, o resultado do processo pelo qual o Estado de justiça da Idade Média, que nos séculos XV e XVI se tornou o Estado administrativo, viu-se pouco a pouco "governamentalizado" (FOUCAULT, 2008a, p. 143-144).

Dentro dessa lógica, o Estado contemporâneo desenvolveu, inicialmente, um conceito de polícia a partir do século XVII de que era "o conjunto dos meios pelos quais é possível fazer as forças do Estado crescerem, mantendo ao mesmo tempo a sua boa ordem desse Estado" (FOUCAULT, 2008a, p. 421). O objetivo da polícia é, então, o controle e a responsabilidade pela atividade dos homens - era importante que os homens fossem virtuosos, obedientes, trabalhadores (FOUCAULT, 2008a, p. 432, apud VALENTE, 2016, p.85-86), na medida em que essa atividade se constitui elemento diferencial na força do Estado. 
Para Foucault, a polícia, desde sua gênese, é organizada para a regulamentação urbana (FOUCAULT, 2008a, p. 452):

(...) a polícia nos séculos XVII e XVIII foi, a meu ver, essencialmente pensada em termos do que poderíamos chamar de urbanização do território. Tratava-se, no fundo, de fazer do reino, de fazer do território inteiro uma espécie de grande cidade, de fazer que o território fosse organizado como uma cidade, com base no modelo de uma cidade e tão perfeitamente quanto uma cidade.

Na continuidade, ainda sobre urbanização e policiamento, afirmou (FOUCAULT, 2008a, p. 453):

(...) evoco simplesmente essas duas palavras para que vocês tenham todas as conotações, todos os fenômenos de eco que pode haver nessas duas palavras e com todos os deslocamentos e atenuações de sentido que pode ter havido no decorrer do século XVIII, mas, no sentido estrito dos termos, policiar e urbanizar é a mesma coisa.

Essa relação íntima entre urbanização e policiamento, destacada por Foucault, encontra-se presente nos estudos criminológicos acerca do delito, no que se denomina de prevenção do crime por meio do desenho arquitetônico e urbanístico. Assim, mediante olhar bem específico e estatístico, detecta-se a correlação entre espaços da cidade e eventos delitivos, o que orienta para ações preventivas por intermédio da reestruturação urbana e do desenho arquitetônico. Como ensina Molina e Gomes (2002, p. 307), referidas ações visam a neutralizar o elevado risco criminógeno ou vitimário que ostentam certos espaços, assim como modificar, também de forma satisfatória, a estrutura "comportamental" e "motivacional" do vizinho ou habitante destes lugares.

No final do século XVIII a razão econômica que surge dá novo conteúdo à governamentalidade. Essa forma contemporânea, intimamente ligada ao pensamento econômico liberal, não enxerga a população como simples súditos submetidos ao soberano que se transforma, cresce, decresce, se desloca. A população, assumida em sua "naturalidade", dará origem a novas ciências e tipos de intervenção, como a medicina social ou a higiene pública, mas também a demografia (VALENTE, 2016, p.87). Para Foucault, a nova governamentalidade terá então por objetivo instituir mecanismos de segurança para garantir os processos intrínsecos à população (FOUCAULT, 2008a, p. 474, apud VALENTE, 2016, p. 88).

A disciplina e segurança surgem como modos de controle e de exercício de poder, como, por exemplo, num conjunto de uma população. Assim, surgem diferentes tratamentos do espaço, seja pela disciplina, seja pela segurança. Foucault (2008a, p. 19) por meio do texto 
Métropolitée tratou do modo de imposição de uma oligarquia expressada pela capital de seu modo de agir e imposição de suas leis e ordens. No citado texto escrito por Alexandre de Maître, Foucault refere-se por meio de uma metáfora arquitetônica como se deveria conceber a construção das cidades, que tinham acentuados crescimentos no período, e as formas de controle que esse poder soberano seria exercido no território. Foucault afirma:

A capital deve dar o exemplo dos bons costumes. A capital deve ser o lugar em que os oradores sacros sejam os melhores e melhor se façam ouvir, deve ser também a sede das academias, pois as ciências e a verdade devem nascer aí para então se difundir no resto do país. E, enfim, um papel econômico: a capital deve ser o lugar do luxo para que constitua um lugar de atração para as mercadorias que vem do estrangeiro, ao mesmo tempo deve ser o ponto de redistribuição pelo comércio de certo número de produtos fabricados, manufaturados, etc.

Segundo Judith Revel é com a governamentalidade moderna que se coloca pela primeira vez o problema da população, vista não como "a soma dos sujeitos de um território, o conjunto de sujeitos de direito ou a categoria geral da 'espécie humana', mas objeto construído pela gestão política global da vida dos indivíduos" (REVEL, 2005, p. 55, apud VALENTE, 2016, p. 88).

Oksala afirmou que o controle e a subjugação de populações conjugam técnicas científicas como tratamento médico, normalização de comportamentos, racionalização de mecanismos de segurança e planejamento urbano, por exemplo. Os mecanismos de poder e conhecimento assumem responsabilidade pelo processo de vida com o objetivo de otimizálo, controlá-lo e modificá-lo (OKSALA, 2013, p.321, apud VALENTE, 2016, p. 89).

Importante destacar que a segurança como manifestação do exercício de poder é racionalizada com vista a manutenção de um sistema, por meio do manejo dos instrumentos de diversas áreas que incidem sobre a vida dos indivíduos, como a medicina, a economia, o planejamento urbano, dentre outros. De outro modo, a segurança como política pública é programa de governo que se utilizará de princípios e instituições do poder constituído para a consecução de seus fins, e que, na atualidade, revela ter em seu centro a Polícia, o Judiciário e o sistema prisional.

Foucault interpreta o neoliberalismo, a partir da II Guerra Mundial e manifestamente desde os anos 1960, não como uma ideologia ou doutrina política, mas como uma forma específica de governamentalidade, racionalmente refletida e coordenada. A falta de estado não leva a 
falta de um governo, mas uma nova forma de governo (OKSALA, 2013, p. 332-333, apud VALENTE, 2016, p.105).

Nesse diapasão, Wacquant constrói a noção de um novo governo da insegurança social, que foca no controle das populações tidas como problemáticas com o fim de inviabilizá-las por meio da desregulamentação do trabalho e do desmantelamento dos serviços de assistência social. Afirma que a concomitância entre crise mundial, ocorrida na década de 70 , e a desconstrução do welfare state para promover a organização institucional e discursiva do estado penal que, utiliza-o como promotor, em que pese o negue na promoção do estado mínimo, o campo burocrático passa a ter em seu centro a polícia, o aparelho judiciário e o sistema prisional.

Da mesma forma como Foucault aborda a falta de estado como meio para gerar um novo governo, Wacquant (2017, p. 203-220) afirma que o discurso do Estado mínimo não se verifica, já que o neoliberalismo transfere os gastos antes direcionadas a ações sociais para o projeto de Estado penal, em que os gastos públicos com as áreas de segurança, judiciária e carcerária têm um aumento exponencial.

O projeto penal do neoliberalismo encerra um paradoxo: pretende incrementar "mais Estado" nas áreas policial, de tribunais criminais e de prisões para solucionar o aumento generalizado da insegurança objetiva e subjetiva que é, ela mesma, causada por "menos Estado" no front econômico e social nos países avançados do Primeiro Mundo. Isto reafirma a onipotência do Leviatã no domínio restrito da manutenção da ordem pública, simbolizando pela batalha em curso contra a delinquência de rua e a migração clandestina que surgiu em todos os lados, precisamente quando o Estado declara e demonstra ser incapaz de impedir a decomposição do trabalho assalariado e de conter a hipermobilidade do capital que converge para desestabilizar todo o sistema social ao esmagá-lo em um brutal e tentacular movimento de ataque.

(...)

Mais significativamente ainda, o projeto penal do neoliberalismo é muito mais sedutor e muito mais nefasto quando se infiltra nos países atravessados por profundas desigualdades de condições sociais e de oportunidades de vida, privados das tradições democráticas e desprovidos das instituições públicas capazes de amortecer os choques provocados pelas concomitantes transformações do trabalho, dos laços sociais e dos sujeitos no limiar do novo século.

De modo a ratificar essa mudança de curso dos gastos públicos provocada pelo neoliberalismo, importante registrar o pensamento de Milanovic (2016, p. 207-208) que, em obra recente, trata do tema desigualdade no mundo e no qual registra o declínio da classe média nos países desenvolvidos e um menor apoio à promoção de serviços sociais, principalmente os de saúde e educação. Afirma que os ricos preferem o consumo privado 
destes serviços, principalmente em países em desenvolvimento, do que fomentar a prestação pública. Assim, ao invés de financiar estas políticas públicas, os recursos públicos são destinados a ações que envolvem programas de segurança, como o policiamento. Referindo-se aos Estados Unidos da América (EUA), aduz que:

\begin{abstract}
Num artigo influente, Bowles e Jayadev (2005) demonstraram que a percentagem de mão de obra envolvida em serviços de segurança pública e privada e produção de armas tinha aumentado drasticamente nos EUA nas últimas três décadas do século XX. A utilização do trabalho de guarda nos EUA em 1970 era já a mais elevada de todos os países ocidentais, com cerca de 1,6 trabalhadores do setor de segurança para cada 100 trabalhadores, mas disparou para mais de 2 por cento em 2000. Bowles e Jayadev estimam que mais de cinco milhões de trabalhadores nos EUA estejam empregados num trabalho de guarda. Além disso, afirmam que o trabalho de guarda é mais predominante em países mais desiguais.
\end{abstract}

Conclui Milanovic (2016, p. 208), que as últimas três décadas econômicas conduzem ao separatismo social (ricos e pobres). Anunciou que referida bifurcação social tem muitas implicações: em termos políticos, a classe média torna-se cada vez mais irrelevante; a produção desloca-se no sentido de bens de luxo e as despesas sociais mudam de uma concentração no ensino e nas infraestruturas para o policiamento.

\title{
2.1. A segurança pública na cidade do Rio de Janeiro
}

De modo racionalmente refletido e coordenado surge o programa de Unidades de Polícia Pacificadora, num território em que a segurança pública é o centro do debate, somado a um ambiente social frágil e de grande desigualdade, que é característica muito presente no Brasil. Nesse aspecto, pautado na atual lógica neoliberal e tendo como base as ideias de governamentalidade, referidas unidades surgem como forma de controle militar de territórios considerados perigosos e em que se originariam a face mais violenta da criminalidade da cidade. Soares afirma que em "vários Estados, a matriz da violência é o tráfico de armas e de drogas, que se realiza no atacado e no varejo" (SOARES, 2003, p. 76, apud MATIOLLI e PINHEIRO, 2014).

Os assentamentos informais, tão marcantes no cenário carioca, tendo como destaque a sua geografia, já que os coloca lado a lado com bairros nobres da cidade, passam a ser o alvo de políticas de segurança ao longo das últimas décadas. Como afirmam Matiolli e Pinheiro (2014), processo concomitante com o da expansão do comércio ilegal da droga que, pela sua territorialização, vai inserir as "favelas" em uma nova chave de criminalização, que não 
substitui as anteriores, mas, monta com elas um "edifício complexo" de exercício de poder, como diria Foucault. Por trás do exercício de poder por este edifício complexo, está a preocupação com o controle social e o esvaziamento político (com a tolerância à ocupação ou o clientelismo), ou a repressão, aos movimentos contestatórios dos "favelados".

As favelas são vistas pelo tráfico de drogas como espaço seguro para o desenvolvimento de suas atividades. Carvalho (2013, p. 291-293) afirma que o que se observa nos últimos trinta anos foi um aumento do uso da força tanto pelos grupos ligados ao tráfico como pelas intervenções estatais (órgãos policiais) no enfrentamento e combate à grupos criminosos. 0 Governo do então Governador Sérgio Cabral parecia que iria adotar a mesma linha. No ano de 2007, logo no primeiro ano de governo (2007-2010), operacionalizou o que se chamaria de megaoperação, no Complexo do Alemão, caracterizado pelo seu cunho bélico e opressor. O resultado foram dezenove mortes e pouca desarticulação do tráfico ${ }^{6}$. Um ano depois foi apresentado o programa de Unidades de Polícia Pacificadora, que parecia indicar uma mudança de rumo na política de segurança com foco na "pacificação" por meio de ações policiais de proximidade ou de policiamento comunitário. Segundo as autoridades, por meio do programa seria possível implementar outras políticas públicas, principalmente as que se inserem no campo social.

Ainda segundo Carvalho (2013, p. 294-295) o programa prevê a contratação de novos policiais, treinados sob novos modelos pautados nos direitos humanos. A finalidade era gerar uma nova imagem da Polícia, desassociada das práticas violentas e arbitrárias. Atrelada a essa nova postura institucional, que se pauta no policiamento de proximidade, pelo menos em seus discursos oficiais, a finalidade de "pacificação" unia-se à de "integração" destes territórios ao tecido urbano. Assim, a imagem de coesão social e de manutenção de segurança e da ordem pública, por meio de pacificação, estaria viabilizada para que as demais políticas públicas, executadas por outros órgãos, fossem executadas.

Assim, as Unidades de Polícia Pacificadora atuariam em espaços da cidade fluminense nomeados como favelas por meio da "pacificação" e teriam como fim a diminuição de confrontos armados promovidos por facções criminosas ligadas ao tráfico de drogas, bem como o de proporcionar a imagem de cidade segura, tanto para as classes mais abastadas

\footnotetext{
6 Jornal Extra. Infoglobo Comunicação e Participações S/A (1996-2018). Diário. Disponível em: https://extra.globo.com/noticias/rio/megaoperacao-no-alemao-deixa-19-mortos-681274.html
} 
da sociedade fluminense como para o capital que deseja aportar na cidade, principalmente motivado pelas oportunidades de negócios proporcionadas pelos megaeventos.

No campo aberto para outras políticas públicas surge o que se denomina de UPP Social, programa desenvolvido pela Prefeitura do Rio de Janeiro com a ONU-Habitat, que tinha como objetivos fomentar a participação da sociedade civil, dos moradores das favelas pacificadas para identificar as demandas locais, e a construção de um plano de desenvolvimento para estas “comunidades" (CARVALHO, 2013, p. 295).

Neste contexto é interessante a reflexão de Oliveira (2014, p. 146) que faz um comparativo entre as semelhanças históricas de dominação entre colonizadores e índios e as atuais políticas de segurança no Rio de Janeiro, com destaque para as unidades policiais específicas para atuar em favelas. Afirmou que as UPPs trouxeram uma nova retórica de pacificação, não pautada somente na tutela para a guerra, mas na conjugação de atos repressivos com benefícios materiais e ações assistenciais. No entanto, quando trata desta questão por meio da tutela, afirma que:

os planos de ação são estabelecidos e executados pelo tutor (ou por outros por ele delegados) sem qualquer participação ativa nem a possibilidade de sua interferência nos métodos ou nos objetivos. Assim, embora os programas governamentais muitas vezes definam metas a serem cumpridas e benefícios a serem recebidos pelas populações tuteladas, na realidade o que é fielmente executado são as ações repressivas e de controle, em geral de interesse de terceiros, as demais raramente saindo do papel.

O que se constata é um controle de fluxo da população e de regulamentação dos hábitos dos moradores das favelas em que foram instaladas as UPPs, como a definição pela polícia do horário de funcionamento do comércio, controle da realização de atividades culturais e festivas privadas, e a regulamentação do serviço de transporte. Como salientou Carvalho (2013, p. 300-303) "a favela tem um novo dono?".

Em consulta ao histórico do projeto, constata-se que as ações militares sempre foram executadas de forma quase exemplar e com baixíssima participação do grupo social objeto das medidas. De outro modo, as ações no campo social ou não iniciaram ou operaram de forma precária e descontínua. Prova disso é que a UPP Social, que como citado acima, foi idealizada para caminhar ao lado das ações militares ${ }^{7}$, na atualidade praticamente inexiste e

\footnotetext{
7 Prefeitura da Cidade do Rio de Janeiro. Disponível em: http://www.rio.rj.gov.br/documents/91329 Le34c132d-ada5-4aa6-8fdd-971507e85654
} 
sempre foi alvo de profundas críticas quando ainda operava, inclusive do próprio Secretário de Segurança Pública do Governo do Estado do Rio de Janeiro à época ${ }^{8}$.

\title{
3. A inviabilidade econômica do programa e a seletividade na
}

\section{instalação}

O Programa de Unidades de Polícia Pacificadora foi criado no final do ano de 2008, após a escolha da cidade do Rio de Janeiro para sediar alguns jogos e a grande final da Copa do Mundo de Futebol FIFA, e segundo o próprio sítio eletrônico do programa ${ }^{9}$ qualifica-se como:

\begin{abstract}
A Unidade de Polícia Pacificadora (UPP) é um dos mais importantes programas de Segurança Pública realizado no Brasil nas últimas décadas. Implantado pela Secretaria de Estado de Segurança do Rio de Janeiro, no fim de 2008, o Programa das UPPs - planejado e coordenado pela Subsecretaria de Planejamento e Integração Operacional - foi elaborado com os princípios da Polícia de Proximidade, um conceito que vai além da polícia comunitária e tem sua estratégia fundamentada na parceria entre a população e as instituições da área de Segurança Pública.

O Programa engloba parcerias entre os governos - municipal, estadual e federal e diferentes atores da sociedade civil organizada e tem como objetivo a retomada permanente de comunidades dominadas pelo tráfico, assim como a garantia da proximidade do Estado com a população.

A pacificação ainda tem um papel fundamental no desenvolvimento social e econômico das comunidades, pois potencializa a entrada de serviços públicos, infraestrutura, projetos sociais, esportivos e culturais, investimentos privados e oportunidades.

O Estado do Rio de Janeiro possui 38 UPPs e a polícia pacificadora conta com um efetivo atual de 9.543 policiais. As UPPs em operação abrangem aproximadamente 264 territórios. Cabe ressaltar que os efeitos proporcionados pelo programa extrapolam as comunidades pacificadas, se estendendo a suas áreas adjacentes, beneficiando direta e indiretamente uma população bem maior. $O$ programa também está na Baixada Fluminense, com a UPP Mangueirinha.
\end{abstract}

Dentre o exposto, destaca-se que a ideia de pacificação se dá por meio do conceito de polícia de proximidade, num diálogo entre a população e as instituições da área de segurança pública, sendo que é executada por uma força policial militarizada em que o diálogo não é a sua melhor característica, em que pese os esforços no treinamento de novos

8 Jornal O Estado de São Paulo. Grupo Estadão (1995-2018). Disponível em: http://brasil.estadao.com.br/noticias/rio-de-janeiro,beltrame-critica-falta-de-apoio-ao-projeto-dasupps,10000081999

${ }^{9}$ http://www.upprj.com/index.php/o_que_e_upp 
policiais. No que concerne ao objetivo, circunscreve-se na retomada permanente de comunidades dominadas pelo tráfico, com o fim de permitir o desenvolvimento social e econômico destas comunidades.

Ocorre que um estudo recente realizado pela própria Secretaria de Segurança Pública do Rio de Janeiro, tornado público por meio da impressa ${ }^{10}$, revelou que o Estado do Rio de Janeiro possui nada menos que 843 áreas dominadas por bandos armados. 0 mais curioso é que entre as dez regiões que registram mais casos de letalidade violenta no Estado, seis abrigam unidades do programa de polícia pacificadora.

O Balanço de Indicadores da Política de Pacificação (2007-2015), estudo realizado pelo Instituto de Segurança Pública - ISP, autarquia vinculada à Secretaria de Estado de Segurança Pública (SESEG), revelou, segundo critérios da própria Secretaria, quais seriam as áreas elegíveis a receber unidades do Programa de Polícia Pacificadora. O mapa das áreas elegíveis com e sem unidades do programa segue abaixo:

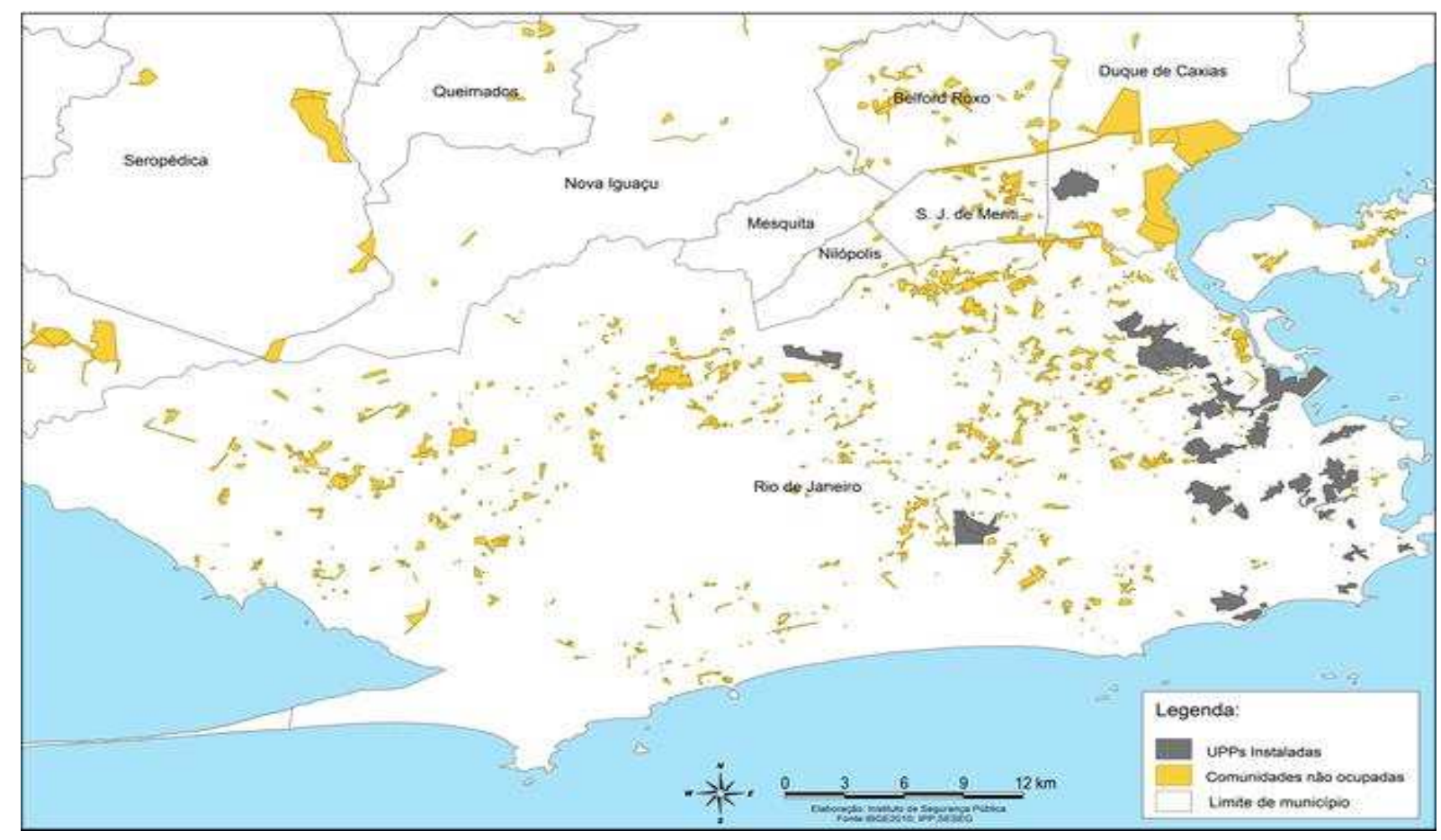

Figura 1 - Áreas elegíveis com e sem Unidades de Polícia Pacificadora Fonte: Instituto de Segurança Pública - ISP, http://www.isp.rj.gov.br/Conteudo.asp?ident=62.

10 Jornal Extra. Infoglobo Comunicação e Participações S/A (1996-2018). Diário. Disponível em: https://extra.globo.com/casos-de-policia/guerra-do-rio/documento-sigiloso-da-secretaria-de-segurancarevela-que-rio-tem-843-areas-dominadas-por-bandos-armados-21710694.html 
O mapa indica que as áreas em cinza seriam que aquelas já possuem as Unidades de Polícia Pacificadora e as amarelas seriam as elegíveis e que não possuem as referidas unidades. Como se pode depreender, os territórios que fariam jus ao programa são numerosos e sequer contemplam os municípios de Niterói e São Gonçalo, integrantes da região metropolitana do Estado do Rio de Janeiro e que também possuem localidades com as mesmas características.

Um olhar descuidado poderia indicar que, para a efetiva implementação, só faltaria o devido planejamento do programa. No entanto, o alto custo de cada uma das unidades revela a sua inviabilidade econômica e que dentro de qualquer planejamento, referida informação relevantíssima ou já era sabida ou, ao menos, previsível. Assim, diante da impossibilidade de instalação em todas as áreas que a cidade necessita, o programa adota critérios seletivos em que a finalidade é atender às classes rica e média cariocas e a de conceber uma imagem de cidade segura para os investidores. Referidas questões serão tratadas a seguir.

Conforme afirma Gaffney, o Rio de Janeiro possui mais que 900 favelas, mas até a Copa do Mundo só 39 foram pacificadas. Quase todas essas estão dentro dos chamados anéis olímpicos e há uma literatura robusta que indica que essa estratégia territorial de implementação é fartamente voltada para os interesses de capital e para garantir a infraestrutura dos megaeventos esportivos (Gaffney, 2015).

Característica marcante das UPPS é o policiamento ostensivo. Assim, o programa torna-se extremamente caro, o que torna irreal a sua aplicação em todo o território. Segundo dados de 2012, para cada 100 policiais em atuação em uma UPP (esse é considerado o número mínimo) o custo anual seria de 6 milhões $^{11}$.

Segundo a promessa de campanha realizada nas eleições de 2010, o então candidato do PMDB prometeu pacificar todas as comunidades do estado dominadas pelo tráfico de drogas ou pela milícia e contratar 25 mil novos policiais militares, sendo 12 mil para as UPPs $^{12}$. Com base nos referidos dados e com um simples cálculo aritmético, pode-se

\footnotetext{
${ }^{11}$ Revista Exame. Abril Mídia S/A. Disponível em: https://exame.abril.com.br/brasil/a-falencia-das-upps/ 12 Jornal O Globo. Infoglobo Comunicação e Participações S/A (1996-2018). Disponível https://oglobo.globo.com/brasil/eleicoes-2010/confira-as-promessas-do-governador-sergio-cabral-paracobrar-acoes-do-governador-reeleito- 4986900
} 
concluir que apenas este incremento no número de policiais para o programa importaria num aumento de gastos com segurança na ordem de $\mathrm{R} \$ 720.000 .000,00$ (setecentos e vinte milhões de reais) por ano, já que cada grupo de 100 policiais representa um valor aproximado de 6 milhões por ano (12.000:100 = $120 \times \mathrm{R} \$ 6.000 .000=\mathrm{R} \$ 720.000 .000)$.

Assim, reforça-se o argumento de que as 38 unidades até hoje instaladas priorizavam lugares estratégicos no sentido de viabilizar a imagem de cidade segura e apta para receber os grandes eventos que iria sediar nos anos de 2014 e 2016, até porque a sua implementação em todos os territórios necessários seria inviável ante seu elevado custo.

Com poucas exceções, os locais eleitos para a instalação das unidades se encontram em áreas nobres da cidade, onde há enorme concentração de turistas e nas quais vivem as classes mais abastadas da sociedade carioca, nos principais corredores de acesso à cidade, como a Linha Vermelha, que liga o Aeroporto Internacional ao Centro e Zona Sul, a Avenida Brasil, principal porta de saída rodoviária da cidade, o entorno do Estádio do Maracanã, que viria a sediar alguns jogos e a grande final da Copa do Mundo de Futebol FIFA, além de importantíssimos eventos nos Jogos Olímpicos, como os de abertura e de encerramento, e a Linha Amarela, importante acesso à Barra da Tijuca e Jacarepaguá, local onde veio a ser construído o "Parque Olímpico". O programa revela como objetivo o de assegurar o controle de populações que viviam em espaços tidos como geradores de crimes violentos, para transformar estes locais em espaços seguros e a cidade confiável aos investimentos, e isso passava necessariamente pelo sucesso em sediar os megaeventos, garantindo que eventos violentos não atrapalhariam sua execução.

Como ratificam Matiolli e Magalhães (2013, apud MATIOLLI e PINHEIRO, 2014), a "política de pacificação parece estar conectada com os processos mais amplos da gestão urbana do Rio de Janeiro e dos circuitos internacionais de circulação do capital contemporâneo. Vide a distribuição geográfica das UPPs".

Para se ter uma melhor compreensão do que se acaba de afirmar, o mapa abaixo demonstra a localização das Unidades de Polícia Pacificadora, em que se evidencia claramente a mencionada concentração: 
Mapa das Unidades de Polícia Pacificadora do Rio

Vila Kennedy, ocupada nesta quinta (13), será a próxima a receber uma UPP

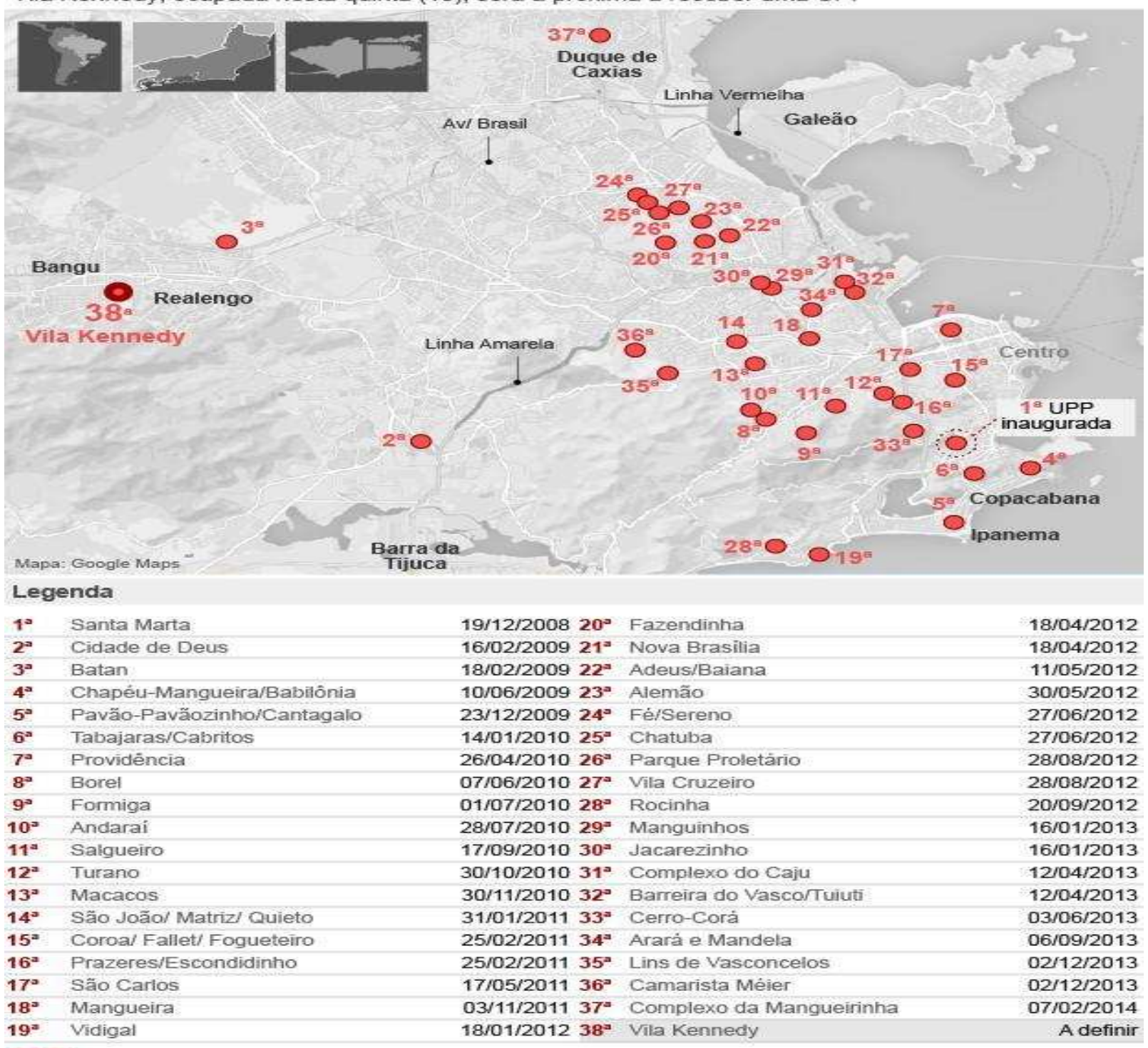

com/br

Figura 2 - Localização das Unidades de Polícia Pacificadora

Fonte: G1, http://g1.globo.com/rio-de-janeiro/noticia/2014/03/pm-realiza-22-acoes-no-rio-para-monitorarmigracao-da-vila-kennedy.html

O quadro que revela as localizações das unidades do programa torna-se ainda mais alarmante quando conjugado com os dados divulgados pelo Instituto de Segurança Pública (ISP), da Secretaria de Segurança Pública do Rio de Janeiro, que revelam os dados acerca da taxa de homicídios de 2016 para a região metropolitana do Estado do Rio de Janeiro, o que inclui a capital fluminense. 


\section{Segurança Pública e Cidadã}

Taxa de homicídios, a cada 100 mil habitantes (letalidade violenta)

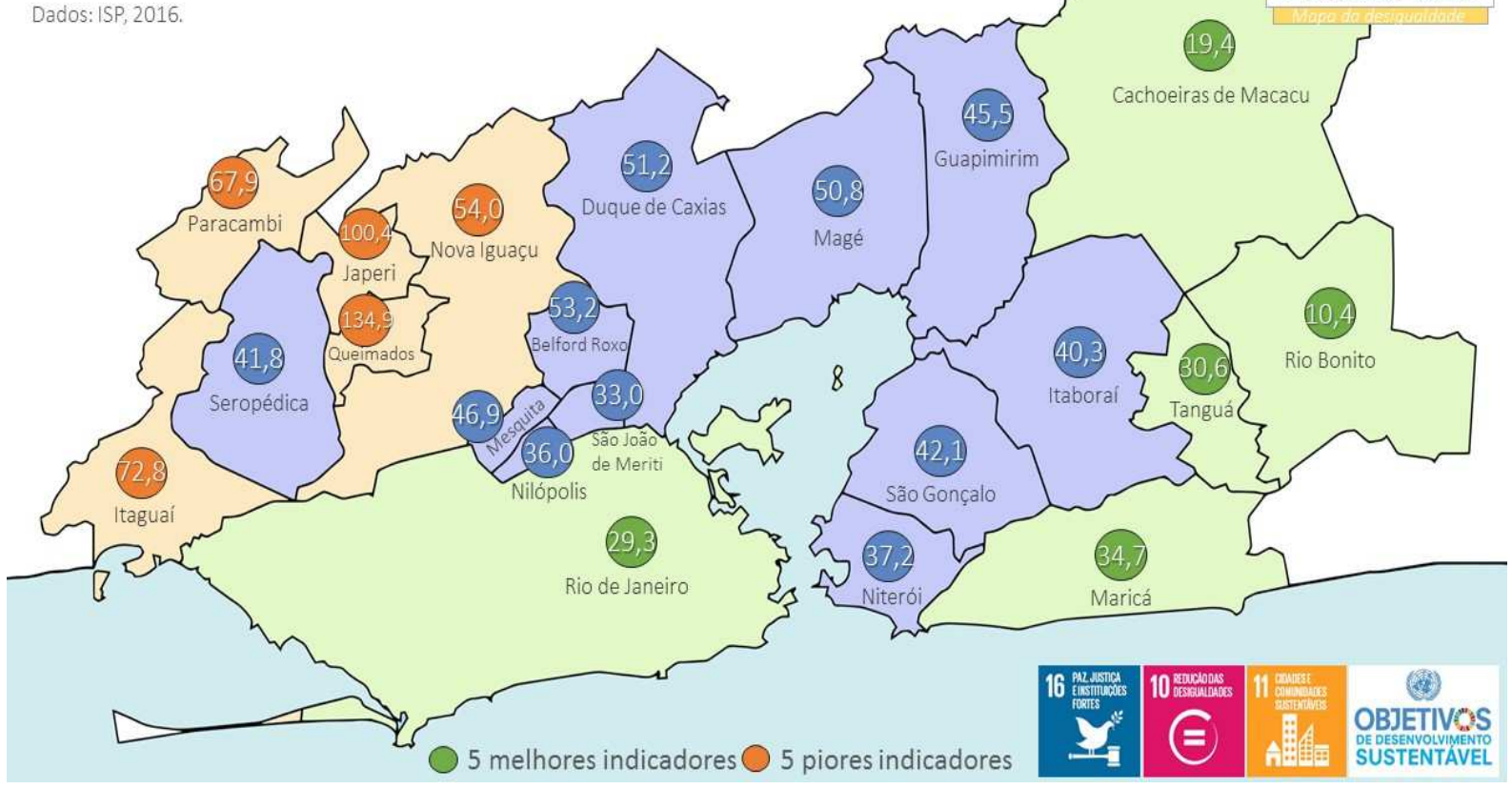

Figura 3 - Taxas de homicídio - Região Metropolitana do Rio de Janeiro - Ano 2016

Fonte divulgação: Casa Fluminense. Mapa da Desigualdade 2016 (http://casafluminense.org.br/mapa-dadesigualdade/). Fonte dos dados: ISP, 2016.

Como se pode observar, outros municípios da região metropolitana do Rio de Janeiro possuem taxas de homicídios elevadíssimas, como Queimados e Japeri (dados em cor laranja), e nenhum deles foi contemplado com sequer uma Unidade de Polícia Pacificadora. De outro modo, a cidade do Rio de Janeiro classifica-se entre as cinco com os melhores índices (dados na cor verde).

Como os dados da taxa de homicídio datam do ano de 2016, poder-se-ia aventar que a Capital possuiria taxas de homicídio superiores a de outras regiões do Estado quando do início do programa, como no caso de Japeri e Queimados que integram a Baixada Fluminense. No entanto, o comparativo entre os dados das séries históricas da taxa de homicídios da Capital e da Baixada Fluminense não permite referida conclusão. 


\begin{tabular}{|c|c|c|c|}
\hline \multirow[b]{2}{*}{ Ano } & \multicolumn{3}{|c|}{ CAPITAL } \\
\hline & $\begin{array}{l}\text { Letalidade } \\
\text { Violenta }\end{array}$ & Po pulaçప̆o & $\begin{array}{c}\text { Taxa por } 100 \mathrm{mil} \\
\text { hab. }\end{array}$ \\
\hline 1991 & 3.571 & 5.480 .768 & 65,2 \\
\hline 1992 & 3.701 & 5.492 .909 & 67.4 \\
\hline 1993 & 3.874 & 5.507 .300 & 70,3 \\
\hline 1994 & 4.192 & 5.521 .492 & 75,9 \\
\hline 1995 & 3.831 & 5.535 .481 & 69,2 \\
\hline 1996 & 3.156 & 5.551 .538 & 56,8 \\
\hline 1997 & 2.906 & 5.612 .944 & 518 \\
\hline 1998 & 2.185 & 5.687 .440 & 38,4 \\
\hline 1999 & 2.659 & 5.762 .826 & 46,1 \\
\hline 2000 & 3.147 & 5.857 .904 & 53,7 \\
\hline 2001 & 2.984 & 5.902 .592 & 50,6 \\
\hline 2002 & 3.465 & 5.947 .622 & 58,3 \\
\hline 2003 & 3.495 & 5.992 .995 & 58,3 \\
\hline 2004 & 3.456 & 6.038 .714 & 57,2 \\
\hline 2005 & 3231 & 6.084 .782 & 53,1 \\
\hline 2006 & 3.286 & 6.131 .201 & 53,6 \\
\hline 2007 & 3.354 & 6.177 .974 & 54,3 \\
\hline 2008 & 2877 & 6.225 .104 & 46,2 \\
\hline 2009 & 2.902 & 6.272 .594 & 46,3 \\
\hline 2010 & 2.205 & 6.320 .446 & 34,9 \\
\hline 2011 & 1.783 & 6.355 .949 & 28,1 \\
\hline 2012 & 1.557 & 6.390 .290 & 24,4 \\
\hline 2013 & 1.613 & 6.429 .922 & 25,1 \\
\hline 2014 & 1.552 & 6.453 .682 & 24,0 \\
\hline 2015 & 1.562 & 6.476 .631 & 24,1 \\
\hline 2016 & 1.909 & 6.498 .837 & 29.4 \\
\hline 2017 & 2.131 & 6.548 .415 & 32,5 \\
\hline
\end{tabular}

\begin{tabular}{|c|c|c|c|}
\hline \multirow[b]{2}{*}{ Ano } & \multicolumn{3}{|c|}{ BAIXADA FLUMINENSE } \\
\hline & $\begin{array}{l}\text { Letalidade } \\
\text { Violenta }\end{array}$ & Populaçăo & $\begin{array}{c}\text { Taxa por } 100 \mathrm{mil} \\
\text { hab. }\end{array}$ \\
\hline 2000 & 1.915 & 3.382 .829 & 56,6 \\
\hline 2001 & 2.022 & 3.408 .274 & 59,3 \\
\hline 2002 & 2.219 & 3.434 .026 & 64,6 \\
\hline 2003 & 2.437 & 3.460 .091 & 70,4 \\
\hline 2004 & 2.169 & 3.486 .474 & 62,2 \\
\hline 2005 & 2.300 & 3.513 .181 & 65,5 \\
\hline 2006 & 2.104 & 3.540 .217 & $59 A$ \\
\hline 2007 & 2.091 & 3.567 .588 & 58,6 \\
\hline 2008 & 2.135 & 3.595 .300 & 59.4 \\
\hline 2009 & 2.112 & 3.623 .359 & 58,3 \\
\hline 2010 & 1.776 & 3.651 .771 & 48,6 \\
\hline 2011 & 1.617 & 3.673 .365 & 44,0 \\
\hline 2012 & 1.489 & 3.694 .249 & 40,3 \\
\hline 2013 & 1.881 & 3.718 .369 & 50,6 \\
\hline 2014 & 2.218 & 3.733 .142 & 59.4 \\
\hline 2015 & 1.702 & 3.747 .408 & $45, A$ \\
\hline 2016 & 2.100 & 3.761 .477 & 55,8 \\
\hline 2017 & 2.301 & 3.791 .666 & 60,6 \\
\hline
\end{tabular}

Tabela 1 - Séries históricas das taxas de homicídio da Capital e da Baixada Fluminense Fonte: ISP (http://www.ispdados.ri.gov.br/Arquivos/SeriesHistoricasLetalidadeViolenta.pdf)

Quando se compara os dados a partir de 2008, ano de inicio do programa, com os dados de 2016, conclui-se que: i) o programa foi capaz de diminuir a taxa de letalidade na cidade do Rio de Janeiro, mas não de forma sustentada, pois a partir do ano de 2016 a referida taxa retoma o seu crescimento e o próprio programa começa a ser contestado, com propostas para reformulação, redução, ou até mesmo o seu fim; e ii) desde o ano de 2008 a cidade do Rio de Janeiro não possui os piores índices de letalidade. Ademais, em 2013 a taxa na cidade do Rio de Janeiro era de 25,1, enquanto que na Baixada Fluminense era de 50,6, mais que o dobro do índice da capital, mas, mesmo assim, nenhuma unidade foi direcionada para os territórios mais violentos.

Relembre-se que o objetivo deste artigo não é o de afirmar que a cidade do Rio de Janeiro não poderia ter sido comtemplada com unidades de polícia pacificadora, mas a forma como foi estruturado o programa, privilegiando-se áreas nobres e importantes pontos estratégicos para os megaeventos que iriam ser sediados pela cidade. A conclusão é a de que não se tratava de política pública de segurança voltada para todo o Estado, nem mesmo para toda a cidade do Rio de Janeiro, apesar das reiteradas promessas dos Governantes de que o programa iria ser implantado em todo o Estado. 
A todo contexto somam-se as recentes informações de que o Governo do Estado do Rio de Janeiro deseja reduzir de 38 para 20 o número de Unidades de Polícia Pacificadora ${ }^{13}$. A justificativa, como já prevista, é a falta de recursos orçamentários disponíveis para manter o número de unidades atuais.

Há ainda um dado alarmante, o de que grupos armados que foram expulsos quando da implantação de cada unidade teriam se deslocado para outras partes da cidade e do Estado (favelas), pois a área de cobertura do programa é bem inferior ao que seria necessário. OLIVEIRA (214, p. 148) diz que os antigos problemas parecem ter sido deslocados de uma parte para outra da cidade, para longe das áreas frequentadas por turistas, mas não resolvidos. A seletividade do programa e o seu único fim de controle de populações para conceber a imagem de cidade segura, sem ações efetivas de políticas públicas em outros setores parecem ser o motivo para o declínio da imagem de sucesso que o programa teve no seu nascedouro.

\section{Considerações finais}

A Administração Municipal da cidade do Rio de Janeiro, com o apoio dos governos Estadual e Federal, adota o modelo de planejamento estratégico e utiliza os grandes eventos (Copa do Mundo de Futebol e Jogos Olímpicos) como instrumento de marketing para divulgar o nome da cidade no cenário internacional e atrair investimentos privados. No entanto, como um dos pressupostos para que referido modelo atrativo pudesse se estabelecer, era de fundamental importância que fosse apresentado um ambiente seguro, de uma cidade sem conflitos. Como o Rio de Janeiro sofre de crônica falta de segurança, por se caracterizar como cidade de grande desigualdade social, e como estava diante de dois grandes eventos internacionais, formulou-se o programa de Unidades de Polícia Pacificadora, que, sob o argumento de pacificar e reintegrar áreas da cidade dominadas pela violência, instalou diversas unidades em sítios da cidade próximos a bairros nobres e dos aparelhos esportivos

13 Jornal O Globo. Infoglobo Comunicação e Participações S/A (1996-2018). Disponível em: https://g1.globo.com/ri/rio-de-janeiro/noticia/seguranca-do-ri-estuda-acabar-com-18-upps.ghtml 
em que se iriam realizar os eventos, tendo a ação melhor executada sido a repressão policial.

O tema criminalidade afeta diretamente a questão da chegada de investimentos à cidade, e a imagem de cidade segura era fundamental para a captação de investimentos pelo mercado da cidade. Recente reportagem da Revista Isto é Dinheiro com o título "De abraços abertos sobre o caos" ilustra bem o caso, ao afirmar que a insegurança pública no Rio de Janeiro vem gerando prejuízos à economia local há muitos anos e que nem mesmo os Jogos Olímpicos conseguiram melhorar o quadro social fluminense. Ainda segundo a reportagem, a Federação das Indústrias do Rio de Janeiro (FIRJAN) teria feito uma sondagem e revelado que $47 \%$ dos empresários do Estado apontaram que o tema criminalidade influenciaria nas decisões acerca do local para novos investimentos, percentual acima da média registrada no Brasil, de $35 \%{ }^{14}$.

O que se conclui é que, após dez anos, referido programa não possuía o pressuposto anunciado de integrar à cidade comunidades dominadas por grupos armados por meio do conceito de polícia de proximidade e que viabilizaria a execução de outras ações públicas, principalmente as de natureza social. O que se notou foi a busca pelo controle de locais estratégicos para a diminuição do alto grau de violência, com o fim de transmitir a imagem de cidade segura, apta a sediar grandes eventos e atrativa aos investimentos. Assim, parece que se confirma a hipótese de que o programa das Unidades de Polícia Pacificadora não passou de mero instrumento dentro da lógica do planejamento estratégico, que se insere num contexto liberal de cidade-empresa, cidade-competitiva, colocada numa "vitrine" em busca de investimentos privados.

Por fim, como bem destacou OLIVEIRA (2014, p. 148), moradores de comunidades que receberam o programa começaram, após cinco anos de seu início, a demonstrar insatisfação com as ações unilaterais do poder público e que a não implementação da UPP Social é um dos aspectos principais. Em verdade, as ações privilegiavam grandes obras de impacto midiático, como o teleférico do Alemão, sem consultas efetivas à comunidade que, insatisfeita, era reprimida com ações policiais. Infelizmente a exclusiva ação repressiva ainda

14 Revista Istoe Dinheiro, ed. 1068, de 04/05/2018. Editora Três. Disponível em: https://www.istoedinheiro.com.br/de-bracos-abertos-sobre-o-caos/ 
continua a ser a lógica recorrente no campo da segurança pública no Estado do Rio de Janeiro.

\section{Referências bibliográficas}

CARVALHO, Monique Batista. A política de pacificação de favelas e as contradições para a produção de uma cidade segura. Rio de Janeiro: Revista O Social em Questão. Ano XVI, no 29, 2013, p. 285-308.

CHAMUSCA, Pedro. Governança e regeneração urbana: entre a teoria e algumas práticas. Tese de Doutoramento, 2012. Repositório Aberto da Universidade do Porto: http://hdl.handle.net/10216/67273, 400p.

FERNANDES, José. O planeamento urbano e a coesão social: a perspectiva europeia e o caso de Portugal. Revista Cidades, 2006, Vol. 3, no 5, p. 11-36. ISSN 2448-1092.

FERNANDES, José \& CHAMUSCA, Pedro. O neotradicional, a elitização e a turistificação: o triunfo do neoliberalismo visto desde o centro da cidade do Porto. In 'A jangada de pedra' - geografias Ibero-AfroAmericanas: atas do XIV colóquio Ibérico de geografia, Guimarães, 2014. Associação Portuguesa de Geógrafos: http://hdl.handle.net/1822/35660, p. 1388-1393.

FOUCAULT, Michel. Segurança, território, população. Curso dado no Collège de France (1977-1978). São Paulo: Martins Fontes, 2008a. ISBN 978-85-336-2377-4.

GAFFNEY, Christopher. Segurança pública e grandes eventos no Rio de Janeiro. In CASTRO, Demian Garcia; GAFFNEY, Christopher; NOVAES, Patrícia Ramos; RODRIGUES, Juciano Martins; SANTOS, Carolina Pereira dos; JUNIOR, Orlando Alves dos Santos (orgs). Rio de Janeiro: os impactos da copa do mundo 2014 e das olimpíadas 2016. 1a ed. Rio de Janeiro. Letra Capital, 2015, p. 145-164.

HARVEY, David. Do gerenciamento ao empresariamento: a transformação da administração urbana no capitalismo tardio. Espaço e Debates, 1996, no 39, p. 48-64. ISSN 2317-2762.

HARVEY, David. A produção capitalista do espaço. São Paulo: Annablume, 2006. ISBN 978-8574194964.

MATIOLLI, Thiago Oliveira Lima; PINHEIRO, Alan Brum. Urbanização e "Pacificação": Políticas de consolidação da reprodução global do capital nas favelas cariocas. In Seminário Nacional de Urbanização de Favelas (I URBFAVELAS), São Bernardo do Campo, 2014. Anais, UFAbc, v. 1. p. 1-17.

MILANOVIC, Branko. A desigualdade no mundo: uma nova abordagem para a era da globalização. Coimbra: Conjuntura Actual Editora, 2016. ISBN 978-989-694-239-7.

MOLINA, Antonio García-Pablo e GOMES, Luiz Flávio. Criminologia: introdução e seus fundamentos teóricos. 4a ed. rev. atual. e amp. São Paulo: Editora Revista dos Tribunais, 2002. ISBN 85-203-1940-8.

OLIVEIRA, João Pacheco de. Pacificação e tutela militar na gestão de populações e territórios. Revista Mana, 2014, Vol. 20, no 01, p. 125-161. ISSN 0104-9313.

VALENTE, Júlia Leite. UPPs: governo militarizado e a ideia de pacificação. 1ạ ed. Rio de Janeiro: Revan, 2016. ISBN 978-857-106-563-5.

VAINER, Carlos. Pátria, empresa e mercadoria: notas sobre a estratégia discursiva do planejamento estratégico urbano. In: ARANTES, Otília; VAINER, Carlos; MARICATO, Ermínia. A cidade do pensamento único: desmanchando consensos. Petrópolis: Vozes, 2000, p. 75-104. ISBN 85.326.2384-0.

WACQUANT, Loic. Rumo à militarização da marginalização urbana. Revista Discursos Sediciosos. Ano 1, 2007 no 15 e 16, p. 203-220. ISBN 9771413988001. 